\title{
Megaloblastic Anemia : Clinico-hematological Profile in 50 Children
}

\author{
Ravinder K Gupta, Sunil Dutt Sharma* and Ritu Gupta** \\ Department of Pediatrics, Acharya Shri Chander College of Medical Sciences, Sidhra, Sunil Child Care Centre, ${ }^{*}$ \\ Bari Brahmina and Child Care Centre,** Nai Basti, Jammu.
}

\section{ABSTRACT}

Objectives: The present study was planned to evaluate the varying clinico- hematological manifestations in 50 children diagnosed as megaloblastic anemia over a four year period. An attempt has been made to find out relative prevalence of cobalamin and folate deficiency in children with megaloblastic anemia.

Material and Methods: All anemic children with or without bleeding manifestations had their peripheral blood smear examined. Complete hemogram including platelet count and mean corpuscular volume (MCV) were carried out in each child using Coulter counter.

Results: This study shows that in any malnourished and anemic child presenting with bleeding manifestations, a strong suspicion of megaloblastic anemia should be entertained. Anemia is not the only problem in these children, as is evident from the finding of neutropenia and thrombocytopenia. Also cobalamin deficiency appears to be emerging as a significant contributor to nutritional megaloblastic anemia. J Med Sci 2009;12(2):49-52

Key words: Megaloblastic anemia, Cobalmin, Folate, Thrombocytopenia

\section{Introduction}

Anemias are the most important disorders of blood in infancy and early childhood. These result in significant morbidity and mortality in children and constitute a public health problem of considerable importance. ${ }^{1}$ Anemia is generally defined as a reduction in red cell mass or blood hemoglobin concentration characterized by decreased oxygen carrying capacity of blood which results in tissue anoxia producing various signs and symptoms. Anemia is not a diagnosis in itself but merely an objective sign of presence of disease. Anemia in children differs from those of adults as they tend to be more pronounced and develop rapidly. As much as $51 \%$ children in $0-4$ years and

\section{Reprint request:}

Dr. Ravinder K Gupta

Associate Professor, Department of Pediatrics, (ASCOMS), Sidhra, Jammu.

E-mail:drrk_gupta2000@yahoo.com
$46 \%$ children 5-12 years are anemic in developing regions. ${ }^{1-3}$

Megaloblastic anemia is one of the important causes of anemias in children. It is not an infrequent entity in poor socioeconomic condition. Nutritional mega-loblastic anemia in children occurs commonly among undernourished or malnourished societies of tropical and subtropical countries. The commonest age is $3-18$ months with maximum number of cases being in 9-12 months. ${ }^{2-6}$ These children are generally exclusively breast-fed by mothers who are undernourished and have poor blood levels of folate and cobalamin. ${ }^{5-7}$ This condition has protean manifestations in childhood, sometimes mimicking a hematological malignancy like leukemia. A great clinical importance is required in diagnosing this clinical entity as it responds to exceedingly well to treatment.

Folate deficiency is considered to be more important cause of megaloblastic anemia and very little emphasis has been given to cobalamin deficiency. Over the last three decades the prevalence of folate deficiency seems to have fallen from 
$70-75 \%$ to $2-10 \%$ as reported in various studies in children and adults from different regions. ${ }^{47}$ Hence cobalamin deficiency appears to be emerging as a significant contributor to nutritional megaloblastic anemia.

The present study evaluates the varying clinicohematological manifestations in 50 children diagnosed as megaloblastic anemia over a four year period. In this study an attempt has been made to find out relative prevalence of cobalamin and folate deficiency in children with megaloblastic anemia.

\section{Subjects and Methods}

Fifty children (6 months - 6 years) diagnosed as megaloblastic anemia (hemoglobin less than $10 \mathrm{~g} / \mathrm{dl}$, and MCV more than $90 \mathrm{fl}$ ) over a period of four year (May 2004 to April 2008) were prospectively studied. All anemic children with or without bleeding manifestations had their peripheral blood smear examined. Complete hemogram including platelet count and mean corpuscular volume (MCV) were carried out in each child using Coulter counter. All the cases with macrocytic blood picture were subjected to bone marrow examination to confirm the diagnosis of megaloblastic anemia. Serum $B_{12}$ and folic acid could be estimated by radioimmuno-assay in 29 children. The diagnosis of megaloblastic anemia was established on the basis of macrocytic PBF and megaloblastic bone marrow. Biochemically pure vitamin $\mathrm{B}_{12}$ deficiency and folic acid deficiency were diagnosed when serum levels were below $80 \mathrm{pg} / \mathrm{ml}$ and $3 \mathrm{ng} / \mathrm{ml}$, respectively. ${ }^{5-7}$ Iron studies were done as an additional investigation for further ruling out concomitant iron deficiency. ${ }^{8}$ Relevant investigations were also done in case of various associated infections.

\section{Results}

The children were in the age group of 12 months to 16 years with male predominance (male : female ratio being1.3:1). All the children belonged to peri-urban areas. About 23 children had normal nutritional status while 7, 6 and 4 children belonged to grade II, III and IV respectively as per IAP classification.

The varying clinical features are shown in Table 1. The peculiar features were $6(12 \%)$ presented with bleeding manifestations. The bleeding was mainly into the skin and subcutaneous tissue. Three children had epistaxis. Infantile tremor syndrome like features were seen in 3 $(6 \%)$ children. All the children had pallor on examination. Hepatomegaly (up to $4 \mathrm{~cm}$ ) and spleno-megaly were seen in $19(38 \%)$ and $5(10 \%)$ respectively. There were no neurological deficits in any of the studied children.

The serum bilirubin levels ranged from $1.6 \mathrm{mg} / \mathrm{dl}$ to $3.4 \mathrm{mg} / \mathrm{dl}$ with predominance of indirect component thus suggesting mild hemolysis.
The children were put on oral folic acid ( $5 \mathrm{mg} /$ day) or/and intramuscular vitamin $B_{12}$ (100 ig/day) for 4 weeks. Initially vitamin $B_{12}$ was given daily for a week followed by alternate day administration and then twice a week injection. Proper dietary advice was given in all cases. Three patients, who were severely anemic also, received blood transfusions. Antibiotics were adminis-tered in infective cases. Follow-up of patients showed improvement in all cases except one. The child who succumbed was severely malnourished with signs of multiple vitamin deficiency and bronchopneumonia.

\section{Discussion}

Deficiency of vitamin $B_{12}$ and folate most commonly results in megaloblastic anemia. All Megalo-blastic anemias are characterized by ineffective erythropoeisis, a kinetic term that describes active erythropoesis with premature death of cells, a decreased output of RBCs from the bone marrow, and, conse-quently, anemia. ${ }^{2-5}$

Megaloblastic anemia is a distinct type of anemia characterized by macrocytic RBC's and typical morphological changes in RBC precursors. The precursors are larger than the cells of same stage and maturation and exhibit disparity in nuclear-cytoplasmic maturation. Both vitamin $B_{12}$ and folic acid are required in the synthesis of nucleoproteins; at the cellular level with resultant impairment of DNA synthesis and to a lesser extent, RNA and protein.

Children usually present with generalized weakness, fatigue, failure to thrive, or irritability. Other common findings include pallor, glossitis, vomiting, diarrhea, icterus, paraesthesias, hypotonia, seizures, tremors, developmental regression, neuropsychiatric changes, hemorrhages etc. ${ }^{2-6}$

Megaloblastic anemia presents with protean manifestations as experienced in our study (Table 1). Bleeding most likely due to thrombocytopenia was noticed in $12 \%$ of patients. An earlier series documented bleeding in 17-20\% of patients in megaloblastic anemia. ${ }^{6,7}$ Hemorrhagic

Table-1: Clinical features $(\mathrm{n}=50)$

\begin{tabular}{lclc}
$\begin{array}{l}\text { Presenting } \\
\text { symptoms }\end{array}$ & $\begin{array}{c}\text { Number } \\
(\%)\end{array}$ & Signs & $\begin{array}{c}\text { Number } \\
(\%)\end{array}$ \\
\hline Pallor & $50(100)$ & Pallor & $50(100)$ \\
\hline Fever & $26(52)$ & Hepatomegaly & $19(38)$ \\
\hline Cough/coryza & $19(52)$ & Pedal edema & $12(24)$ \\
\hline Diarrhea & $10(20)$ & Icterus & $7(14)$ \\
Bleeding manifestations & $6(12)$ & Petechiae & $5(10)$ \\
Vomiting & $6(12)$ & Hyperpigmentation & $5(10)$ \\
Tremors & $3(6)$ & Splenomegaly & $5(10)$ \\
\hline Lathergy & $3(6)$ & Breathlessness & $4(8)$ \\
\hline
\end{tabular}


emergencies like intracranial bleeding and gut bleeding though not well appreciated in this disease have been rarely seen. ${ }^{9,10}$ Thrombocytopenia is believed to be due to impaired DNA synthesis resulting in ineffective thrombopoiesis. Icterus, not an infrequent feature in this disease was noticed in seven children (14\%) in our study. It is explainable on the basis of decreased life span of RBC's and to premature destruction of developing megaloblasts in the marrow. ${ }^{9-11}$ Three children in our study presented with infantile tremor syndrome, a syndrome often associated with megaloblastic anemia due to nutritional vitamin $\mathrm{B}_{12}$ deficiency. ${ }^{12,13}$ Hyper-pigmentation of dorsum of hands and fingers though considered an important diagnostic sign for this disease $\mathrm{e}^{3,14}$ was witnessed in only five children. The presence of fever in $52 \%$ of patients was significant, the commonest cause being infection to which the individual is much more susceptible in this disease due to impaired intracellular killing of ingested bacteria by neutrophils and macro-phages. ${ }^{6,7,9-11}$

Thrombocytopenia was reported in $30 \%$ cases and leucopenia in $14 \%$ cases in our study. Megaloblastic anemia is an important cause of cytopenias (pancytopenia and bicytopenia) but to the best of our knowledge, there are not many studies quoting its incidence. An earlier series reported an incidence of pancytopenia in $43.8 \%$ and bicytopenia in $80.5 \%$ cases. ${ }^{6,7,11}$ The varying results in the two series could be due to the difference in the duration of anemia which is proportional to the development of cytopenias. ${ }^{11}$ It is generally believed that as severity of anemia increases, thrombocytopenia develops followed by neutropenia. ${ }^{6,711}$ The trends of serum levels of $B_{12}$ and folic acid though done in only 29 cases clearly revealed predominance of $\mathrm{B}_{12}$ deficiency. Relative prevalence of cobalamin and folate deficiency in cases with megaloblastic anemia has been a subject of some debate. The studies in early sixties showed that folate deficiency was more prevalent, a trend similar to one observed in developed countries. However, compared to developed countries cobalamin deficiency was more common in India. ${ }^{15}$ Over the last four decades, the proportion of cases having cobalamin deficiency appears to have increased. This increase in cobalamin deficiency appears to be a global phenomenon as the recent reports appearing from other developing countries indicate. In a Mexican study on preschool children no folate deficiency was seen, but $41 \%$ had cobalamin deficiency. ${ }^{16}$ A Zimbabwean study on megaloblastic anemia (including adults and children) reported cobalamin deficiency being three times more common than folate deficiency. ${ }^{17}$ Out of 29 cases in which serum levels of vitamin $B_{12}$ and folate levels were estimated, 9 cases had low levels of vitamin $B_{12}$ while one case had pure folate deficiency and 12 cases showed combined deficiency. In our study, folate deficiency was not as low as reported by others. We feel that this changing trend might be related to National Nutritional Anemia Prophylaxis
Program introduced in 1970 and revised to National Nutritional Anemia Control Program in 1991, in which 5 mg of folic acid is given with iron to all pregnant women. ${ }^{18,19}$ Folate stores at birth would generally be normal in children of these mothers. It could be due to poor nutritional status of children, mothers and vegetarian habits. ${ }^{15}$ Seven patients who had normal $B_{12}$ and folate levels inspite of marrow megaloblastosis could be due to administration of vitamins by private practitioners before admission to the hospital though such history was not available. Other less common manifestations resulting from deficiency of these hematopoeitic micronutrients in children include neuro-developmental effects and abnormal movements. Neural tube defects result from deficiency in mothers during pregnancy. Bone loss resulting in osteopenia, osteoporosis and pathological fractures and cardiovascular effects predisposing to coronary artery disease are observed in adults and elderly patients. ${ }^{2-4,20}$

\section{Conclusions}

On the basis of observations made in this study, it is concluded that in any malnourished and anemic child presenting with bleeding manifestations, a strong suspicion of megaloblastic anemia should be entertained. Anemia is not the only problem in these children, as is evident from the finding of neutropenia and thrombocytopenia. Additionally cobalamin deficiency appears to be emerging as a significant contributor to nutritional megaloblastic anemia.

\section{References}

1. Gupte S, Gupta RK, Gupta R. Iron Deficiency Anemia: A Diagnostic Approach in Children.F K Science 2000;2:175-9.

2. Garder B. Anemias of Inadequate Production. In: Kliegman RM, Behrman RE,Jenson H B, Stanton B F(eds). Nelson Textbook of Pediatrics. 18th edn. Philadelphia, W.B. Saunders 2008:2011-14.

3. Supte S.:Pediatric Hematology. In Gupte S). The Short Textbook of Pediatrics. 10th edn. New Delhi. Jaypee. 2004: 454-62.

4. Cooper BA, Rosenblath DS. Megaloblastic anemia. In: Hematology of Infancy and Childhood, 4th edn. Eds. Nathan DG, Oski FA, Philadelphia, W.B. Saunders, 1993;346-84.

5. Rasmussen SA, Fernhoff PM, Scanlon KS: Vitamin $B_{12}$ deficiency in children and adolescents. F Pediatr 2001;138: 10-17.

6. Gomber S, Kela K, Dingra N. Clinico- hematological profile of megaloblastic anemia. Indian Pediatrics 1998; 35: 55-58.

7. Chandra J, Jain V, Narayan S, Sharma S, Singh V, Kapoor AK, Batra B. Folate and cobalmin deficiency in children. Indian Pediatrics 2002;39:453-57.

8. International Committee for Standardization in Hematology. The measurement of total and unsaturated iron binding capacity in serum. BrF Hematol 1978;38:281-90.

9. Quadsi MI, Dash S, Broor SL, Mehta D. Megaloblastic 
anemia presenting as hemorrhagic emergency. Indian $\mathcal{F}$ Hematol 1988;6:203-5.

10. Levine PH. A qualitative platelet defect in severe vitamin $\mathrm{B}_{12}$ deficiency, response, hyper response and thrombosis after vitamin $\mathrm{B}_{12}$ therapy. Ann Int Med 1973;78:533.

11. Sarode R, Garewal G, Marwaha N, Marwaha RK, Varma S, Ghosh K, et al. Pancytopenia in nutritional Megalo-blastic anaemia, A study from North-West India. Trop Geogr Med 1989;41:331-6.

12. Gupte S. Infantile Tremor Syndrome (ITS). In Gupte S (ed) :Recent Advances in Pediatrics (Special Volume 18: Pediatric Neurology) New Delhi. Jaypee. 2008:431-35.

13. Garewal G, Narang A, Das KC. Infantile tremor syndrome: A vitamin $B_{12}$ deficiency syndrome. F Trop Pediatr 1988; 34: 174-78.

14. Baker SJ, Ignatius $M$, Johnson S. Hyperpigmentation of skin:A sign of vitamin $\mathrm{B}_{12}$ deficiency. Br Med F 1963;1713-15.

15. Chanarin I, Malkowska V, Marie O' Hea A, Rinsper MG,
Price AB. Megaloblastic anemia in a vegetarian Hindu community. Lancet 1985;2:1168-72.

16. Allen LH, Rosado JL, Casterline JE, Mertinaz H, Patricia L, Murioz E, et al. Vitamin B12 deficiency and malabsorption are highly prevalent in rural Mexican communities. Am F Clin Nutr 1995;62:1013-19.

17. Mukiibi JM, Makumbi FA, Gwanzura C. Megaloblastic anemia in Zimbabwe: Spectrum of clinical and hematological manifestations. East Afr Med f 1992;69: 83-7.

18. Gupte S, Gupta RK, Gupta R. Iron Deficiency Anemia : Management and Prevention in Children. $7 K$ Science 2001;3:160-65.

19. Gupta RK, Gupta R. Current Issues for the prevention of iron deficiency anemia amongst young Children. $\mathcal{F} \mathrm{K}$ Science 2004;6:174-75.

20. Rosenblatt DS, Whiteheat VM. Cobalamin and folate deficiency: Acquired and hereditary disorders in children. Semin Hematol 1999;36:19-34. 